\title{
The Biology of Frankia sp. Strains in the Post-Genome Era
}

\author{
David R. Benson, James M. Brooks, Ying Huang, Derek M. Bickhart, and Juliana E. Mastronunzio \\ Department of Molecular and Cell Biology, U-3125, University of Connecticut, Storrs, U.S.A.
}

Submitted 10 June 2011. Accepted 31 July 2011.

\begin{abstract}
Progress in understanding symbiotic determinants involved in the $\mathrm{N}_{2}$-fixing actinorhizal plant symbioses has been slow but steady. Problems persist with studying the bacterial contributions to the symbiosis using traditional microbiological techniques. However, recent years have seen the emergence of several genomes from Frankia sp. strains and the development of techniques for manipulating plant gene expression. Approaches to understanding the bacterial side of the symbiosis have employed a range of techniques that reveal the proteomes and transcriptomes from both cultured and symbiotic frankiae. The picture beginning to emerge provides some perspective on the heterogeneity of frankial populations in both conditions. In general, frankial populations in root nodules seem to maintain a rather robust metabolism that includes nitrogen fixation and substantial biosynthesis and energy-generating pathways, along with a modified ammonium assimilation program. To date, particular bacterial genes have not been implicated in root nodule formation but some hypotheses are emerging with regard to how the plant and microorganism manage to coexist. In particular, frankiae seem to present a nonpathogenic presence to the plant that may have the effect of minimizing some plant defense responses. Future studies using high-throughput approaches will likely clarify the range of bacterial responses to symbiosis that will need to be understood in light of the more rapidly advancing work on the plant host.
\end{abstract}

This brief review focuses on results from post-genome approaches to the biology of Frankia sp. strains and their interactions with host plants. Since genome sequences from three Frankia sp. strains were published in 2007 (Normand et al. 2007), a book (Pawlowski and Newton 2008), two conference proceedings (Chaia et al. 2010a; Sellstedt et al. 2007), and several reviews focusing on themes intrinsic to Frankia spp. and actinorhizal plants have been published. Review topics have included plant-microbe interactions (Kucho et al. 2010; PerrineWalker et al. 2011), root nodule physiology (Persson and Huss-Danell 2009; Valverde and Huss-Danell 2008), infection (Pawlowski 2009; Wall and Berry 2008;), ecology (Benson and Dawson 2007; Chaia et al. 2010b), history (Wheeler et al.

Corresponding author: D. R. Benson; E-mail: david.benson@uconn.edu

Current address of D. M. Bickert: Bovine Functional Genomics Laboratory, USDA-ARS, Building 200, Room 124B, BARC-East, Beltsville, MD 20705, U.S.A.

Current address of J. E. Mastronunzio: Department of Internal Medicine, Section of Infectious Disease, Yale University School of Medicine, 300 Cedar Street, TAC S410, New Haven, CT 06520, U.S.A.
2008), and evolution and diversity (Normand and Fernandez 2009; Swensen and Benson 2008). For work focused on the plant side of the symbiosis, the reader is referred to some recent articles detailing plant signaling pathways and hormonal interactions common among rhizobial, mycorrhizal, and actinorhizal symbioses (Gherbi et al. 2008; Hocher et al. 2011; Laplaze et al. 2008; Markmann et al. 2008; Perrine-Walker et al. 2010, 2011; Svistoonoff et al. 2010).

Frankia sp. strains form $\mathrm{N}_{2}$-fixing root nodule symbioses with plants that are recognized more for their importance in global and local environments than for their food value (Benson and Silvester 1993). Actinorhizal plants typically colonize soils of marginal fertility such as glacial till, volcanic ashfields, sand dunes, chaparral, water-saturated, or even dry soils, and have been used for reforestation or remediation of soils (Benson and Silvester 1993). Representative actinorhizal species are native to all continents, save Antarctica, and habitable environments range from the subarctic to the tropics (Benson and Dawson 2007; Benson et al. 2004). Frankiae growing in plant root nodules contribute substantially to the total terrestrial biologically fixed $\mathrm{N}_{2}$ (Cleveland et al. 1999; Dixon and Wheeler 1986), rendering the fundamental attributes of the symbiosis an attractive target for study at many levels.

Phylogenetically, Frankia sp. strains from the Actinobacteria and the paraphyletic rhizobia from the Alpha- and Betaproteobacteria are quite distant, suggesting that the two major groups of symbionts have solved a functionally similar symbiosis from different directions. At the same time, the pattern of relationships between plant hosts indicates that a potential to form $\mathrm{N}_{2}$-fixing root nodules arose once in the Eurosid 1 clade of Angiosperms followed by repeated losses over time (Clawson et al. 2004; Markmann et al. 2008; Soltis et al. 1995; Swensen and Benson 2008). Thus, one might expect $\mathrm{N}_{2}$-fixing plants to have similar symbiotic determinants but the same might not hold for the microorganisms.

Research on frankial biology remains constrained by the absence of facile methods for inactivating and complementing genes of interest (Kucho et al. 2009). Strains are filamentous and grow slowly relative to most laboratory bacteria (Fig. 1). On solid medium, the best time recorded for colony appearance remains approximately 3 days (Bassi and Benson 2007). On the other hand, three complete genome sequences from strains ACN14a (NC_008278), CcI3 (NC_007777), and EAN1pec (NC_009921) are now well annotated (Normand et al. 2007), with others in the pipeline at the U.S. Department of Energy Joint Genome Institute, including two finished sequences from strains EUN1f (NZ_ADGX00000000) and EuI1c (NC_014666) and one from an unisolated strain living in Datisca glomerata root nodules (NC_015656).

Additional genomes from related actinobacteria are available for comparative work. These include, from the suborder Franki- 
neae (Zhi et al. 2009), the thermoacidophile Acidothermus cellulolyticus 11B (NC_008578) (Barabote et al. 2009), Geodermatophilus obscurus G-20 (NC_013757) (Ivanova et al. 2010) and Nakamurella multipartita type strain Y-104T (NC_013235) (Tice et al. 2010). A close ally of the suborder whose genome is available is Kineococcus aurantiaca SRS30216 (NC_009664) (Bagwell et al. 2008) as well as other related organisms. These actinomycetes are noteworthy for the niches they inhabit. Frankia strains occupy root nodules, Acidothermus spp. grow in acid hot springs (Mohagheghi et al. 1986), Geodermatophilus spp. occupy rocky surfaces in dry desert areas or on historical monuments (Urzi et al. 2001), and Kineococcus spp. can be found on dry or gamma-irradiated substrates (Phillips et al. 2002). The depth of sequencing within the Frankiales and related taxa provides fodder for developing hypotheses. On the other hand, having hypotheses without tools for addressing them places the investigator in the position of Tantalus, grasping at fruit that remains just beyond reach.

\section{Frankia genomes.}

Within the genus, three "clusters" of true Frankia sp. strains (defined by effective nodulation) are recognized phylogenetically, each having a distinct host range (Benson and Dawson 2007; Benson et al. 2004; Normand et al. 1996). A fourth group of noninfective or noneffective strains defines a more deeply branching cluster 4 of related bacteria (Kucho et al. 2010). Cluster 1 strains ("Alnus strains") have only been detected in and isolated from nodules of Alnus spp. in the family Betulaceae and Comptonia, Myrica, and Morella spp. in the family Myricaceae. A subclade within cluster 1 houses the "Casuarina strains" that are limited to nodules of Casuarina and Allocasuarina spp. in the family Casuarinaceae. Cluster 3 "Elaeagnus strains" have a broad host range, being found in nodules from the families Myricaceae, Elaeagnaceae, and Rhamnaceae, and some members of the Casuarinaceae. The cluster 2 "Rosaceous strains" are sister to both clusters 1 and 3 but remain uncultivated; these strains nodulate plants from the families Rhamnaceae (genus Ceanothus), Rosaceae, Datiscaceae, and Coriariaceae (Benson and Dawson 2007; Benson et al. 2004; Normand et al. 1996).

Some unusual features (Normand et al. 2007) of the finished genomes include size disparities of the circular chromosome that range from 5.43 to $8.89 \mathrm{Mbp}$. Present information suggests a correlation between genome size, host range, and persistence in soils (Normand et al. 2007). The smaller genome is from the cluster 1 Casuarina cunninghamiana CcI3. Strains represented by $\mathrm{CcI} 3$ show a degree of host dependence; they are generally not detectable in soils outside the range of their host plants ("Casuarina strains") as assessed by plant trapping experiments (Benson et al. 2004). Codon usage patterns further suggest that strain $\mathrm{CcI} 3$ is evolving toward being a symbiotic specialist by having the fewest number of highly expressed genes (Sen et al. 2008).

The largest genome is from the cluster 3 isolate $(8.98 \mathrm{Mbp}$ for EAN1pec). Similar strains are ubiquitous in soils even in the absence of the host species (Swensen and Benson 2008). This ubiquity is true also of cluster 1 Alnus strains whose one sequenced representative, $\mathrm{ACN} 14 \mathrm{a}$, has an intermediate genome size of $7.36 \mathrm{Mbp}$ and only infects plants from the families Betulaceae and Myricaceae. Thus, in aggregate, Frankia sp. strains form a step gradient of host plant relationships ranging from reliance on the presence of a host to varying degrees of promiscuity. This gradient mirrors genome size and content. An analysis of the evolutionary processes at work using comparative genomics indicated that $\mathrm{CcI} 3$ has lost approximately twice as many genes $(1,054)$ as either ACN14a (466) or EAN1pec (555), and EAN1pec has gained more than twice as many genes $(1,355)$ as either ACN14a (512) or CcI3 (444), largely by duplication and horizontal transfer (Normand et al. 2007).

Genome size variance may partly be driven by the abundance of insertion sequences (IS) (Bickhart et al. 2009; Normand et al. 2007). In cluster 3 strains, IS elements (represented by transposase open reading frames) may be associated with genome expansion through gene duplication, although too few strains have been analyzed to say for certain. On the other hand, in the cluster 1 Casuarina CcI3, transposases are associated with genome reduction through gene deletion (Bickhart et al. 2009). Indeed, the most duplicated gene families in $\mathrm{CcI} 3$ encode for IS element transposases (Normand et al. 2007). ACN14a has relatively few transposases and seems to have the most stable genome (Bickhart et al. 2009). In addition to annotated transposase genes, PSI-BLAST analyses have revealed dozens of transposase remnants in the genomes of both $\mathrm{CcI} 3$ and EAN1pec, indicating substantial and ongoing genome remodeling (Bickhart et al. 2009). This activity is reflected in transcriptome studies that show elevated transcription of transposase genes in stressed cultures (Bickhart and Benson 2011). A relative instability of some frankial phenotypes has been remarked upon in the older literature in terms of changes in pigmentation, substrate utilization, and the overall growth and effectivity of frankial strains; therefore, evidence of genome
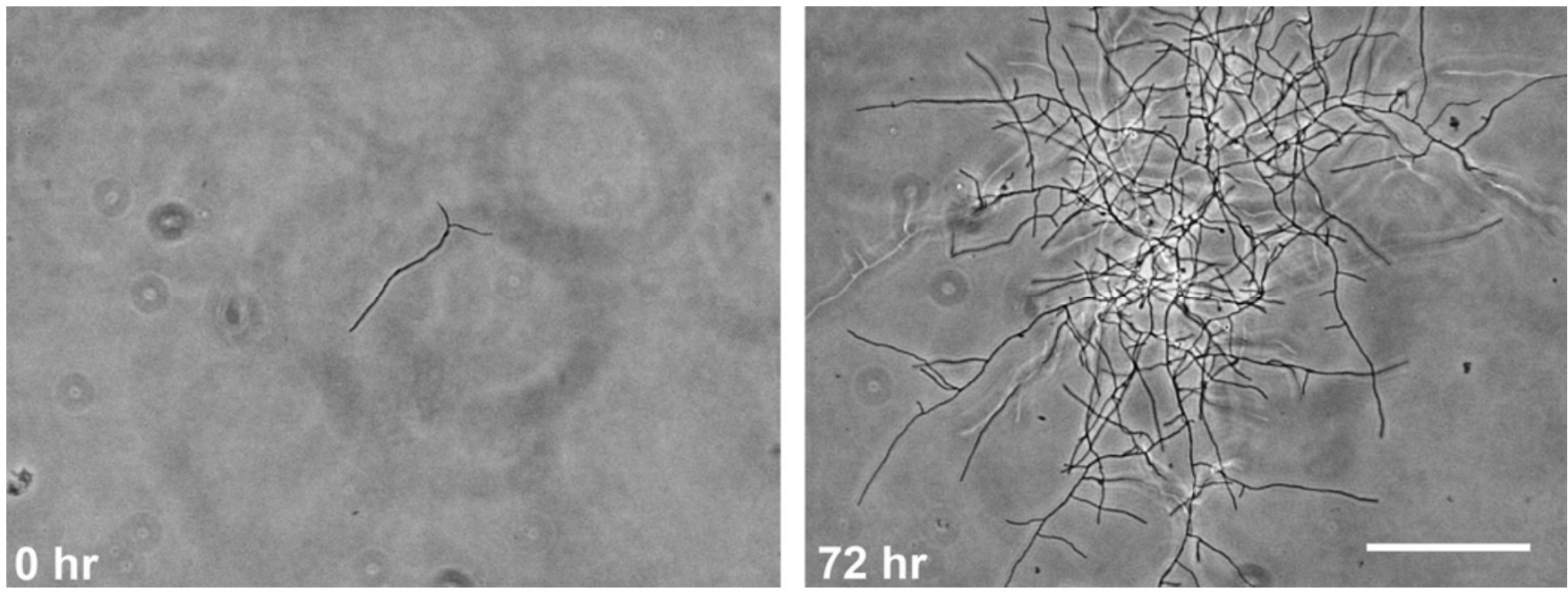

Fig. 1. Growth habit of Frankia sp. strain $\mathrm{CcI} 3$ grown in liquid culture over a period of 3 days. 
instability may not be surprising (Burggraaf and Valstar 1984; Hahn et al. 1988; Prin et al. 1991).

Aside from genome size and plasticity, genes responsible for cell metabolism, growth, and duplication are rather standard. Most frankiae grow on minimal media and are generally limited in the types of carbon and nitrogen sources utilized (Benson and Silvester 1993). The nif genes are central to the symbiosis and their gene order is highly conserved among frankiae and arranged as shown in Figure 2. Interestingly, nif $V$ is found nearly $180^{\circ}$ opposite on the strain EAN1pec genome.

When the first frankial genomes became available, the hunt was on to find homologs of "common nod" (nodABC) genes involved in most rhizobial symbioses. In rhizobia, these genes encode enzymes that synthesize a short oligosaccharide of $\beta$ 1,4 linked $\mathrm{N}$-acetylglucosamine (NodC) that is modified by deacetylation (NodB) and $\mathrm{N}$-acylation $(\operatorname{NodA})$ to produce the lipochitooligosaccharide structure of "nod factor". Further modification of nod factors confers specificity with different legumes. Homologs of nod genes are found only sporadically in frankial genomes and with low similarity to those found in rhizobia sensu latu. NodB homologs are found in all strains and are generally annotated as polysaccharide deacetylases, with Blastp E values of $1.0 \mathrm{e}^{-60}$ to $8.0 \mathrm{e}^{-14}$ when compared with rhizobial "NodB" genes; they seem unlikely to be involved in symbiosis because such NobB homologs are common in many bacteria (Normand et al. 2007). The expression of a $\operatorname{nodB}$ homolog in ACN14a was reported as unchanged in nodules versus cultured cells in a microarray study (Alloisio et al. 2010). At present, the paucity of identifiable nod genes presents a puzzle, considering the recent identification of the common and nodule-specific signaling pathways in nodules of Alnus and Casuarina spp. during infection (Hocher et al. 2011).

Other genes of interest but unproven effect are those encoding enzymes in pathways for auxin biosynthesis, including those for making indole acetic acid (IAA) and phenyl acetic acid. Auxins made by frankiae have long been postulated to be involved in the symbiosis (Berry et al. 1989; Hammad et al. 2003; Peret et al. 2008; Wheeler, et al. 1984). Recent work has indicated that auxins accumulate in infected cells of $C$. glauca root nodules (Perrine-Walker et al, 2010). The accumulation was proposed to be due, in part, to auxin production by Frankia sp. strain $\mathrm{CcI} 3$, having possible effects on cell expansion, cell wall remodeling, or limiting plant responses to the microorganism (Perrine-Walker et al, 2010). Mutants in frankial auxin biosynthesis pathways are not available; therefore, potential roles are difficult to assess. Indeed, genes proposed as encoding the indole-3-acetamide and the indole-3-pyruvate pathways in the Frankia genomes have low similarity to those in other organisms, suggesting that either a novel pathway is operating or that IAA may arise by other means (Gordon and Paleg 1961).

Because actinomycetes are noted for producing a rich variety of secondary metabolites, attention has been paid to the secon- dary metabolomes of frankial strains. Two secondary metabolites from frankiae were structurally characterized before genomes became available. These include a polyketide-derived benzo[a]naphthacene quinone pigment (Gerber and Lechevalier 1984) from Frankia sp. strain R-2 and a polyether ionophore antibiotic from strain AiPs1 named frankiamide (Klika et al. 2003). Since genomes have become available, several gene clusters have been identified by bioinformatics; in total, 65 have been reported, approximately equally distributed among CcI3, Ean1pec, and ACN14a (Nett et al. 2009; Udwary et al. 2011). These clusters were predicted to be involved with the synthesis of a variety of polyketides, nonribosomal peptides, siderophores, and specialized lipids (Udwary et al. 2011). Some gene clusters have been identified from studies on other organisms via similarity searches. For example, genes involved in making the polyketide antibiotic abbysomicin in Verrucosispora maris have similarity to genes in ACN14a and EAN1pec (Gottardi et al. 2011). Genes for making pyoverdine in Pseudomonas aeruginosa have orthologs in CcI3 (Clarke-Pearson and Brady 2008); genes for making cetoniacytone A in Actinomyces sp. strain Lu9419 have similarity to genes in ACN14a (Wu et al. 2009). The same is true of other ribosomally synthesized peptides (Aravind et al. 2010; Udwary et al. 2011; Weber et al. 2009), terpenoids (Komatsu et al. 2008), lantibiotics (Marsh et al. 2010; Severinov et al. 2007), phosphonate derivatives (Shao et al. 2008), and an uncharacterized nonribosomal peptide whose biosynthesis genes are found on plasmid pSmeSM11b in Sinorhizobium meliloti and are similar to a cluster of genes in Frankia sp. strain $\mathrm{CcI} 3$ and the D. glomerata symbiont (Stiens et al. 2007).

In light of the large number of predicted secondary metabolites, three observations can be made. First, aside from those involved in known cellular functions (siderophores, hopanoids, and other lipids), relatively few secondary metabolite biosynthesis gene clusters are shared between frankial strains thus far sequenced, indicating frequent horizontal gene trafficking. Second, aside from frankiamide that has some antimicrobial activity (Haansuu et al. 2001), no biological activity has been reported for any of the secondary metabolites. Third, actual structures have not been reported for any of the compounds whose genes have been identified. Thus, at present, any role in symbiosis is unknown.

\section{Post-genome approaches.}

In the absence of a way to mutate specific genes, comparative proteomics and transcriptomics have been used as approaches for dissecting the symbiosis. These approaches have included separating proteins on two-dimensional gel electrophoresis followed by matrix-assisted laser desorption/ionization timeof-flight mass spectrometry (MALDI-TOF) analysis (Alloisio et al. 2007), shotgun analysis of peptide mixtures using liquid chromatography coupled to tandem mass spectrometry (LCMS/MS) of trypsin digested samples (Mastronunzio and Benson

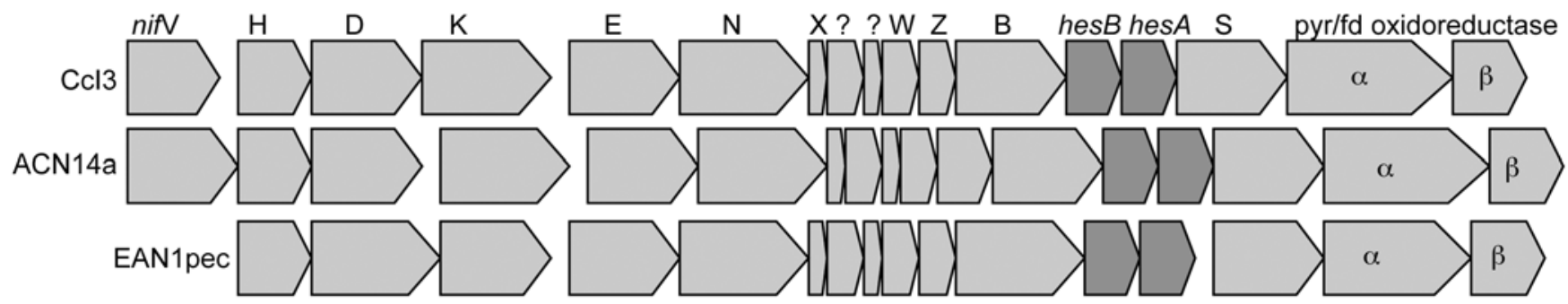

Fig. 2. Alignment of Frankia sp. strain nif gene clusters derived from genome sequences. Variability includes the relocation of nifV in EAN1pec to a distal region of the genome. 
2010; Mastronunzio et al. 2009; Udwary et al. 2011), transcriptome analysis using DNA microarrays (Alloisio et al. 2010), suppression subtractive hybridization (Yamaura et al. 2010), and whole-transcriptome shotgun sequencing (RNA-seq) (Bickhart and Benson 2011). In some cases, studies have been limited to cultures, and others have included comparisons with root nodules.

\section{Proteomics.}

The first proteomic study to take advantage of the Frankia genomes used two-dimensional gel separation, followed by MALDI-TOF analysis of individual protein spots from cultures grown with and without ammonium (Alloisio et al. 2007). This approach led to the identification of 126 proteins. Nif proteins were not identified in the $\mathrm{N}_{2}$-fixing culture, perhaps because their limitation to vesicles compared with more abundant vegetative cells led to an overall lower concentration. Other proteins involved in $\mathrm{N}$-assimilation (glutamine synthetase II) or oxidative stress were more abundant in N-limited cells, and succinate dehydrogenase was diminished. Many intracellular proteins were found in culture supernatants, indicating cell lysis over the growth period used (Alloisio et al. 2007), an issue also found in later studies (Mastronunzio et al. 2009).

Using a similar approach, the effect of phenolic extracts from Myrica gale and Morella cerifera seed on protein patterns of strains ACN14a, M16467, and Ea112 was investigated (Bagnarol et al. 2007). Of 115 proteins whose staining intensity was altered, 50 were identified, 20 were upregulated, and 30 downregulated. Many of the former were involved in general metabolism, iron transport, and oxidative stress, or were chaperones. The greatest change in expression involved an Fe$\mathrm{Zn}$ superoxide dismutase and two tellurium resistance proteins whose homologs in other bacteria have been implicated in survival during pathogenesis (Valkovicova et al. 2011). The overall pattern was one of adaptation to plant defense responses (Bagnarol et al. 2007). Similar conclusions were drawn from microarray studies looking at the effect of specific flavonoids on gene expression (as well as growth and $\mathrm{N}_{2}$ fixation) of Frankia sp. strains in culture (Popovici et al. 2010). In all, 22 genes were significantly affected, of which 8 had an annotated function. Upregulated genes included a multidrug efflux pump, ruberythrin, a fur family repressor, and a transcriptional regulator with homology to $w h i B$ involved in differentiation, sporulation, or antibiotic production in other actinomycetes. The latter is highly conserved among all frankial genomes but its function is unknown. Overall, the effects of plant phenolic extracts on Frankia sp. strains in culture again suggest a response to host plant defense compounds, although how these responses might affect the symbiosis is unknown.

Other bioinformatic and shotgun proteomic approaches have led to hypotheses concerning plant interactions. For example, bioinformatic studies on the exoproteome of ACN14a, CcI3, and EAN1pec indicate that frankiae in general produce few exoenzymes (Mastronunzio et al. 2008, 2009). The depauperate nature of the frankial exoproteome has been confirmed in culture and in symbiosis by direct shotgun proteomic (LC-MS/MS) approaches (Mastronunzio and Benson 2010; Mastronunzio et al. 2009). Few secreted proteins are found in strain CcI3 culture supernatants, and this observation is consistent with microarray experiments that revealed little upregulation of signal peptide-containing exoenzyme genes in strain ACN14a nodules (Alloisio et al. 2010).

Of 1,031 proteins detected from CcI3 in root nodules, 42 predicted signal-peptide-containing proteins were found (Mastronunzio et al. 2009). Similarly, 73 and 53 putative secreted proteins, out of over 1,000 proteins detected in each nodule type, were identified from Frankia strains in field-col- lected root nodules of Alnus incana and Elaeagnus angustifolia, respectively (Mastronunzio and Benson 2010; Mastronunzio et al. 2009). Among those detected, solute-binding proteins accounted for approximately half, especially those annotated as branched-chain amino acid and peptide-binding proteins. Of six hydrolase exoenzymes detected, none was identified as degrading cell wall polysaccharides (Mastronunzio et al. 2009). These results have led to the hypothesis that frankiae survive in plant cells at least partly by presenting few proteins or microbial-associated molecular patterns (Mackey and McFall 2006) that might trigger host defenses (Mastronunzio et al. 2008). Such a strategy has been observed with some fungal pathogens (Baxter et al. 2010; Kamper et al. 2006). These observations are inconsistent with the hypothesis that Frankia sp. strains depolymerize plant cell wall polymers during nodulation (Igual et al. 2001; Safo-Sampah and Torrey 1988), though it is still possible that some of the more generally annotated glycosidases, esterases, or proteases may contribute to this function. The true situation will likely be found to be more complex once signaling studies have advanced but, presently, Frankia strains seem to present a relatively nonpathogenic visage to the plant.

\section{Transcriptomics.}

Initial transcriptome studies on Frankia spp. used wholegenome DNA microarrays to compare free-living with symbiotic strain ACN14a in root nodules from A. glutinosa, Myrica gale, and Morella rubra (Alloisio et al. 2010). The results provide an excellent data set from which to draw observations and construct hypotheses. Complicating microarray approaches are the necessity of using cells grown in culture to compare with those in symbiosis and the heterogeneous nature of any Frankia cell population that includes those at actively growing hyphal apices, stationary phase cells behind the hyphal apex, and spores and vesicles in culture and symbiosis (Benson and Silvester 1993). Nevertheless, such approaches have recorded, as expected, a strong induction in nodules of genes for nitrogenase and its biosynthesis along with those for hydrogenase (hup2) and iron sulfur cluster biosynthesis (suf). Interestingly, genes for enzymes associated with ammonium assimilation, including $g \ln A$ and $g \ln I I$, encoding the constitutive and N-starvation forms of glutamine synthetase, were diminished in symbiosis. A similar change has been noted in nodule proteomes (Mastronunzio and Benson 2010). These results suggest that symbiotic frankial cells may not perceive $\mathrm{N}$ starvation and that nif genes are regulated by signals other than those involved in $\mathrm{N}$ metabolism, possibly oxygen levels or types and abundance of combined $\mathrm{N}$. Older work has shown that vesicle formation and $\mathrm{N}_{2}$ fixation continue in the presence of amino acids metabolized via glutamate in strain $\mathrm{CpI} 1$; therefore, a similar scenario may be playing out in symbiosis (Zhang and Benson 1992).

In nodules occupied by cluster 1 frankiae, the implications are that ammonium is transferred to the plant from the bacterium The abundance of plant cytosolic glutamine synthetase in infected alder cells supports the idea of ammonia transfer (Guan et al. 1996). On the other hand, in the Datisca/Coriaria type nodules, plant glutamine synthetase is not detectable in infected cells, and amino acids have been hypothesized as being transferred to the plant (Berry et al. 2004). In the latter case, the frankial proteome from the nodule would be predicted to contain high levels of glutamine synthetase but this hypothesis has not yet been addressed.

Also upregulated in symbiosis were frankial genes associated with the TCA cycle, ATP synthase, and electron transport, suggesting a relatively higher requirement for ATP than might be expected during $\mathrm{N}_{2}$ fixation. These results also parallel proteomics work using whole nodules from Alnus and Elaeagnus 
spp. that found an abundance of TCA cycle enzymes and electron transport components (Mastronunzio and Benson 2010). Genes encoding proteins involved in oxidative stress protection showed a mix of up- and downregulation. Overall, microarray studies have not yet identified a "smoking-gun" gene or gene set specific for symbiosis that may dictate symbiotic competence. However, a greater proportion of genes were upregulated versus downregulated in symbiosis (ratio of 2.4:1) than had been reported for similar studies using $S$. meliloti nodules (ratio of 1:3.1) (Alloisio et al. 2010). This observation may mean that frankiae require more aspects of metabolism to be active in symbiosis than rhizobia, perhaps because they are more autonomous and must provide their own protection in dealing with the host environment (Alloisio et al. 2010).

Other transcriptome studies have dealt with Frankia spp. in free-living cultures using RNASeq massively parallel sequencing (Wang et al. 2009). This approach has not yet been applied to nodules but provides a more quantitative view of bacterial transcription and some cautions for future work (Bickhart 2010; Bickhart and Benson 2011). Comparing transcriptomes between younger versus older strain $\mathrm{CcI} 3$ cultures grown on ammonia and $\mathrm{N}_{2}$ indicates more variability with culture age than with nitrogen source. On the other hand, stresses from either $\mathrm{N}$ limitation or culture age seem to create conditions for genome instability. Indeed, 73 of CcI3's 148 transposase genes were transcribed at a higher rate in 5-day old cultures than in 3-day old cultures, and 91 were transcribed more heavily in young cultures growing on $\mathrm{N}_{2}$ than in young cultures grown on ammonia (Bickhart and Benson 2011). This variability with culture age and developmental stage is an important factor affecting various types of "-omics" studies with filamentous organisms like Frankia sp. strains, as noted above with supernatants from older (beyond 5-day) cultures of $\mathrm{CcI} 3$ or ACN14a (Alloisio et al. 2007; Huang and Benson 2011; Mastronunzio et al. 2009).

\section{Prospects.}

Applying newer technologies for accessing the actinorhizal symbiosis from the perspective of the bacterium has provided many insights into symbiotic interactions, albeit without solving the mystery of how the symbiosis is initiated or maintained. Moving forward, RNA-seq-type experiments applied to Frankia spp. in nodules are the logical next step on the path to identifying genes specifically involved in symbiotic signaling and homeostasis beyond what is now known. High-throughput transcriptomic and proteomic studies must take into account the heterogeneity of Frankia cell populations both in culture and in symbiosis that represent an average of cells in different physiological and developmental states, including vegetative and stationary-phase hyphae, spores, and vesicles. The advent of single-cell transcriptomics (Kang et al. 2011) for bacteria may provide a way for assessing the transcriptome in symbiosis at a much higher resolution. Finally, the plant side of the symbiosis has not been addressed here. However, a great deal of information is beginning to accumulate concerning plant signaling pathways and responses, primarily because of technological advances in genetically manipulating the host and the development of a variety of tools for analysis (PerrineWalker et al. 2011). It may well be that plant approaches will provide the road map for finally revealing the determinants of the frankial symbiosis.

\section{LITERATURE CITED}

Alloisio, N., Felix, S., Marechal, J., Pujic, P., Rouy, Z., Vallenet, D., Medigue, C., and Normand, P. 2007. Frankia alni proteome under nitrogen fixing and nitrogen replete conditions. Physiol. Plant. 130:440-453.
Alloisio, N., Queiroux, C., Fournier, P., Pujic, P., Normand, P., Vallenet, D., Medigue, C., Yamaura, M., Kakoi, K., and Kucho, K. 2010. The Frankia alni symbiotic transcriptome. Mol. Plant-Microbe Interact. 23:593-607.

Aravind, L., de Souza, R. F., and Iyer, L. M. 2010. Predicted class-I aminoacyl tRNA synthetase-like proteins in non-ribosomal peptide synthesis. Biol. Direct 5:48.

Bagnarol, E., Popovici, J., Alloisio, N., Maréchal, J., Pujic, P., Normand, P., and Fernandez, M. P. 2007. Differential Frankia protein patterns induced by phenolic extracts from Myricaceae seeds. Physiol. Plant. 130:380-390.

Bagwell, C. E., Bhat, S., Hawkins, G. M., Smith, B. W., Biswas, T., Hoover, T. R., Saunders, E., Han, C. S., Tsodikov, O. V., and Shimkets, L. J. 2008. Survival in nuclear waste, extreme resistance, and potential applications gleaned from the genome sequence of Kineococcus radiotolerans SRS30216. PLoS ONE 3:e3878.

Barabote, R. D., Xie, G., Leu, D. H., Normand, P., Necsulea, A., Daubin, V., Mèdigue, C., Adney, W. S., Xu, X. C., and Lapidus, A. 2009. Complete genome of the cellulolytic thermophile Acidothermus cellulolyticus 11B provides insights into its ecophysiological and evolutionary adaptations. Genome Res. 19:1033-1043.

Bassi, C. A., and Benson, D. R. 2007. Growth characteristics of the slow growing actinobacterium Frankia sp. strain $\mathrm{CcI} 3$ on solid media. Physiol. Plant. 130:391-399.

Baxter, L., Tripathy, S., Ishaque, N., Boot, N., Cabral, A., Kemen, E., Thines, M., Ah-Fong, A., Anderson, R., Badejoko, W., Bittner-Eddy, P., Boore, J. L., Chibucos, M. C., Coates, M., Dehal, P., Delehaunty, K., Dong, S., Downton, P., Dumas, B., Fabro, G., Fronick, C., Fuerstenberg, S. I., Fulton, L., Gaulin, E., Govers, F., Hughes, L., Humphray, S., Jiang, R. H. Y., Judelson, H., Kamoun, S., Kyung, K., Meijer, H., Minx, P., Morris, P., Nelson, J., Phuntumart, V., Qutob, D., Rehmany, A., Rougon-Cardoso, A., Ryden, P., Torto-Alalibo, T., Studholme, D., Wang, Y., Win, J., Wood, J., Clifton, S. W., Rogers, J., Van den Ackerveken, G., Jones, J. D. G., McDowell, J. M., Beynon, J., and Tyler, B. M. 2010. Signatures of adaptation to obligate biotrophy in the Hyaloperonospora arabidopsidis genome. Science 330:1549-1551.

Benson, D. R., and Dawson, J. O. 2007. Recent advances in the biogeography and genecology of symbiotic Frankia and its host plants. Physiol Plant. 130:318-330.

Benson, D. R., and Silvester, W. B. 1993. Biology of Frankia strains, actinomycete symbionts of actinorhizal plants. Microbiol. Rev. 57:293-319.

Benson, D. R., Vanden Heuvel, B. D., and Potter, D. 2004. Actinorhizal symbioses: Diversity and biogeography. Pages 99-129 in: Plant Microbiology. M. Gillings and A. Holmes, eds. Garland Science/BIOS Scientific Publishers, Oxford.

Berry, A.M., Kahn, R.K.S., and Booth, M.C. 1989. Identification of indole compounds secreted by Frankia HFPArI3 in defined culture medium. Plant Soil 118:205-209.

Berry, A. M., Murphy, T. M., Okubara, P. A., Jacobsen, K. R., Swensen, S. M., and Pawlowski, K. 2004. Novel expression pattern of cytosolic Gln synthetase in nitrogen-fixing root nodules of the actinorhizal host, Datisca glomerata. Plant Physiol. 135:1849-1862.

Bickhart, D. M. 2010. Insertion element activity in bacterial genomes. Ph.D. dissertation, Department of Molecular and Cell Biology, University of Connecticut, Storrs.

Bickhart, D. M., and Benson, D. R. Transcriptomes of Frankia sp. strain $\mathrm{CcI} 3$ in growth transitions. BMC Microbiol. 11:192. Published online. doi:10.1186/1471-2180-11-192.

Bickhart, D. M., Gogarten, J. P., Lapierre, P., Tisa, L. S., Normand, P., and Benson, D. R. 2009. Insertion sequence content reflects genome plasticity in strains of the root nodule actinobacterium Frankia. BMC Genomics 10:468-481.

Burggraaf, A. J. P., and Valstar, J. 1984. Heterogeneity within Frankia sp. LDAgpl studied among clones and reisolates. Plant Soil 78:29-43.

Chaia, E., Dawson, J., and Wall, L. 2010a. Special Volume devoted to the 15th International Frankia and Actinorhizal Plant Meeting. Symbiosis $50: 1-2$.

Chaia, E., Wall, L., and Huss-Danell, K. 2010b. Life in soil by the actinorhizal root nodule endophyte Frankia: A review. Symbiosis 51:201226.

Clarke-Pearson, M. F., and Brady, S. F. 2008. Paerucumarin, a new metabolite produced by the $p v c$ gene cluster from Pseudomonas aeruginosa. J. Bacteriol. 190:6927-6930.

Clawson, M. L., Bourret, A., and Benson, D. R. 2004. Assessing the phylogeny of Frankia-actinorhizal plant nitrogen-fixing root nodule symbioses with Frankia 16S rRNA and glutamine synthetase gene sequences. Mol. Phylogenet. Evol. 31:131-138.

Cleveland, C. C., Townsend, A. R., Schimel, D. S., Fisher, H., Howarth, R. W., Hedin, L. O., Perakis, S. S., Latty, E. F., VonFisher, J. C., Elseroad, A., and Wasson, M. F. 1999. Global patterns of terrestrial biological 
nitrogen $\left(\mathrm{N}_{2}\right)$ fixation in natural ecosystems. Global Biogeochem. $\mathrm{Cy}-$ cles 13:623-645.

Dixon, R. O. D., and Wheeler, C. T. 1986. Nitrogen Fixation in Plants. Chapman and Hall, New York.

Gerber, N. N., and Lechevalier, M. P. 1984. Novel benzo[a]naphthacene quinones from an actinomycete Frankia G-2 (ORS 020604). Can. J. Chem. 62:2818-2821

Gherbi, H., Markmann, K., Svistoonoff, S., Estevan, J., Autran, D., Giczey, G., Auguy, F., Peret, B., Laplaze, L., Franche, C., Parniske, M., and Bogusz, D. 2008. SymRK defines a common genetic basis for plant root endosymbioses with arbuscular mycorrhiza fungi, rhizobia, and Frankia bacteria. Proc. Natl. Acad. Sci. U.S.A. 105:4928-4932.

Gordon, S. A., and Paleg, L. G. 1961. Formation of auxin from tryptophan through action of polyphenols. Plant Physiol. 36:838-845.

Gottardi, E. M., Krawczyk, J. M., von Suchodoletz, H., Schadt, S., Mühlenweg, A., Uguru, G. C., Pelzer, S., Fiedler, H.-P., Bibb, M. J., Stach, J. E. M., and Süssmuth, R. D. 2011. Abyssomicin biosynthesis: Formation of an unusual polyketide, antibiotic-feeding studies and genetic analysis. Chembiochem 12:1401-1410.

Guan, C., Ribeiro, A., Akkermans, A. D. L., Jing, Y., Van Kammen, A., Bisseling, T., and Pawlowski, K. 1996. Nitrogen metabolism in actinorhizal nodules of Alnus glutinosa: Expression of glutamine synthetase and acetylornithine transaminase. Plant Mol. Biol. 32:1177-1184.

Haansuu, J. P., Klika, K. D., Söderholm, P. P., Ovcharenko, V. V., Pihlaja, K., Haahtela, K. K., and Vuorela, P. M. 2001. Isolation and biological activity of frankiamide. J. Ind. Microbiol. Biotechnol. 27:62-66.

Hahn, D., Starrenburg, M. J. C., and Akkermans, A. D. L. 1988. Variable compatibility of cloned Alnus glutinosa ecotypes against ineffective Frankia strains. Plant Soil 107:233-243.

Hammad, Y., Nalin, R., Marechal, J., Fiasson, K., Pepin, R., Berry, A. M., Normand, P., and Domenach, A.-M. 2003. A possible role for phenyl acetic acid (PAA) on Alnus glutinosa nodulation by Frankia. Plant Soil 254:193-205.

Hocher, V., Alloisio, N., Auguy, F., Fournier, P., Doumas, P., Pujic, P., Gherbi, H., Queiroux, C., Da Silva, C., Wincker, P., Normand, P., and Bogusz, D. 2011. Transcriptomics of actinorhizal symbioses reveals homologs of the whole common symbiotic signaling cascade. Plant Physiol. 156:700-711.

Huang, Y., and Benson, D. R. 2011. Growth and development of Frankia spp. strain $\mathrm{CcI} 3$ at the single-hypha level in liquid culture. Arch. Microbiol. Online publication. doi:10.1007/s00203-011-0734-5

Igual, J. M., Velázquez, E., Mateos, P. F., Rodríguez-Barrueco, C., Cervantes, E., and Martínez-Molina, E. 2001. Cellulase isoenzyme profiles in Frankia strains belonging to different cross-inoculation groups. Plant Soil 229:35-39.

Ivanova, N., Sikorski, J., Jando, M., Munk, C., Lapidus, A., Del Rio, T. G., Copeland, A., Tice, H., Cheng, J. F., and Lucas, S. 2010. Complete genome sequence of Geodermatophilus obscurus type strain (G-20T). Stand. Gen. Sci. 2:158-167.

Kamper, J., Kahmann, R., Bolker, M., Ma, L.-J., Brefort, T., Saville, B. J., Banuett, F., Kronstad, J. W., Gold, S. E., Muller, O., Perlin, M. H., Wosten, H. A. B., de Vries, R., Ruiz-Herrera, J., Reynaga-Pena, C. G., Snetselaar, K., McCann, M., Perez-Martin, J., Feldbrugge, M., Basse, C. W., Steinberg, G., Ibeas, J. I., Holloman, W., Guzman, P., Farman, M., Stajich, J. E., Sentandreu, R., Gonzalez-Prieto, J. M., Kennell, J. C. Molina, L., Schirawski, J., Mendoza-Mendoza, A., Greilinger, D., Munch, K., Rossel, N., Scherer, M., Vranes, M., Ladendorf, O., Vincon, V., Fuchs, U., Sandrock, B., Meng, S., Ho, E. C. H., Cahill, M. J., Boyce, K. J., Klose, J., Klosterman, S. J., Deelstra, H. J., Ortiz-Castellanos, L., Li, W., Sanchez-Alonso, P., Schreier, P. H., Hauser-Hahn, I., Vaupel, M., Koopmann, E., Friedrich, G., Voss, H., Schluter, T., Margolis, J., Platt, D., Swimmer, C., Gnirke, A., Chen, F., Vysotskaia, V., Mannhaupt, G., Guldener, U., Munsterkotter, M., Haase, D., Oesterheld, M., Mewes, H.W., Mauceli, E. W., DeCaprio, D., Wade, C. M., Butler, J., Young, S., Jaffe, D. B., Calvo, S., Nusbaum, C., Galagan, J., and Birren, B. W. 2006. Insights from the genome of the biotrophic fungal plant pathogen Ustilago maydis. Nature 444:97-101.

Kang, Y., Norris, M. H., Zarzycki-Siek, J., Nierman, W. C., Donachie, S. P., and Hoang, T. T. 2011. Transcript amplification from single bacterium for transcriptome analysis. Genome Res. 21:925-935.

Klika, K. D., Haansuu, J. P., Ovcharenko, V. V., Haahtela, K. K., Vuorela P. M., Sillanpaa, R., and Pihlaja, K. 2003. Frankiamide: A structural revision to demethyl (C-11) cezomycin. Z. Naturforsch. B Anorg. Chem. Org. Chem. 58:1210-1215.

Komatsu, M., Tsuda, M., Mura, S., Oikawa, H., and Ikeda, H. 2008. Identification and functional analysis of genes controlling biosynthesis of 2 methylisoborneol. Proc. Natl. Acad. Sci. U.S.A. 105:7422.

Kucho, K., Kakoi, K., Yamaura, M., Higashi, S., Uchiumi, T., and Abe, M. 2009. Transient transformation of Frankia by fusion marker genes in liquid culture. Microbes Environ. 24:231-240.
Kucho, K.-i., Hay, A.-E., and Normand, P. 2010. The determinants of the actinorhizal symbiosis. Microbes Environ. 25:241-252.

Laplaze, L., Svistoonoff, S., Santi, C., Auguy, F., Franche, C., and Bogusz, D. 2008. Molecular biology of actinorhizal symbioses. Pages 235-259 in: Nitrogen-Fixing Actinorhizal Symbioses. K. Pawlowski and W. E. Newton, eds. Springer, Dordrecht, The Netherlands.

Mackey, D., and McFall, A. J. 2006. MAMPs and MIMPs: Proposed classifications for inducers of innate immunity. Mol. Microbiol. 61:13651371

Markmann, K., Giczey, G. B., and Parniske, M. 2008. Functional adaptation of a plant receptor-kinase paved the way for the evolution of intracellular root symbioses with bacteria. PLoS Biol. 6:e68.

Marsh, A. J., O'Sullivan, O., Ross, R. P., Cotter, P. D., and Hill, C. 2010 In silico analysis highlights the frequency and diversity of type 1 lantibiotic gene clusters in genome sequenced bacteria. BMC Genomics 11:679-700.

Mastronunzio, J., and Benson, D. 2010. Wild nodules can be broken: Proteomics of Frankia in field-collected root nodules. Symbiosis 50:13-26.

Mastronunzio, J. E., Tisa, L. S., Normand, P., and Benson, D. R. 2008. Comparative secretome analysis suggests low plant cell wall degrading capacity in Frankia symbionts. BMC Genomics 9:47-62.

Mastronunzio, J. E., Huang, Y., and Benson, D. R. 2009. Diminished exoproteome of Frankia spp. in culture and symbiosis. Appl. Environ. Microbiol. 75:6721-6728.

Mohagheghi, A., Grohmann, K., Himmel, M., Leighton, L., and Updegraff, D. M. 1986. Isolation and characterization of Acidothermus cellulolyticus gen. nov., sp. nov., a new genus of thermophilic, acidophilic, cellulolytic bacteria. Int. J. Syst. Evol. Microbiol. 36:435-443.

Nett, M., Ikeda, H., and Moore, B. S. 2009. Genomic basis for natural product biosynthetic diversity in the actinomycetes. Nat. Prod. Rep. 26:1362-1384.

Normand, P., and Fernandez, M. 2009. Evolution and diversity of Frankia. Pages 103-125 in: Prokaryotic Symbionts in Plants. K. Pawlowski, ed. Springer, Berlin.

Normand, P., Orso, S., Cournoyer, B., Jeannin, P., Chapelon, C., Dawson, J., Evtushenko, L., and Misra, A. K. 1996. Molecular phylogeny of the genus Frankia and related genera and emendation of the family Frankiaceae. Int. J. Syst. Bacteriol. 46:1-9.

Normand, P., Lapierre, P., Tisa, L. S., Gogarten, J. P., Alloisio, N., Bagnarol, E., Bassi, C. A., Berry, A. M., Bickhart, D. M., Choisne, N. Couloux, A., Cournoyer, B., Cruveiller, S., Daubin, V., Demange, N., Francino, M. P., Goltsman, E., Huang, Y., Kopp, O. R., Labarre, L., Lapidus, A., Lavire, C., Marechal, J., Martinez, M., Mastronunzio, J. E., Mullin, B. C., Niemann, J., Pujic, P., Rawnsley, T., Rouy, Z., Schenowitz, C., Sellstedt, A., Tavares, F., Tomkins, J. P., Vallenet, D., Valverde, C., Wall, L. G., Wang, Y., Medigue, C., and Benson, D. R. 2007. Genome characteristics of facultatively symbiotic Frankia sp. strains reflect host range and host plant biogeography. Genome Res. 17:7-15.

Pawlowski, K. 2009. Induction of actinorhizal nodules by Frankia. Pages 127-154 in: Prokaryotic Symbionts in Plants. K. Pawlowski, ed. Springer, Berlin.

Pawlowski, K., and Newton, W. E., eds. 2008. Nitrogen-Fixing Actinorhizal Symbioses. Springer, Dordrecht, The Netherlands.

Peret, B., Svistoonoff, S., Lahouze, B., Auguy, F., Santi, C., Doumas, P., and Laplaze, L. 2008. A role for auxin during actinorhizal symbioses formation? Plant Signal. Behav. 3:34-35.

Perrine-Walker, F., Doumas, P., Lucas, M., Vaissayre, V., Beauchemin, N. J., Band, L. R., Chopard, J., Crabos, A., Conejero, G., Peret, B., King, J. R., Verdeil, J. L., Hocher, V., Franche, C., Bennett, M. J., Tisa, L. S., and Laplaze, L. 2010. Auxin carriers localization drives auxin accumulation in plant cells infected by Frankia in Casuarina glauca actinorhizal nodules. Plant Physiol. 154:1372-1380.

Perrine-Walker, F., Gherbi, H., Imanishi, L., Hocher, V., Ghodhbane-Gtari, F., Lavenus, J., Benabdoun, F. M., Nambiar-Veeti, M., Svistoonoff, S., and Laplaze, L. 2011. Symbiotic signaling in actinorhizal symbioses. Curr. Protein Pept. Sci. 12:156-164.

Persson, T., and Huss-Danell, K. 2009. Physiology of actinorhizal nodules. Pages 155-178 in: Prokaryotic Symbionts in Plants. K. Pawlowski, ed. Springer, Berlin.

Phillips, R. W., Wiegel, J., Berry, C. J., Fliermans, C., Peacock, A. D., White, D. C., and Shimkets, L. J. 2002. Kineococcus radiotolerans sp. nov., a radiation-resistant, gram-positive bacterium. Int. J. Syst. Evol. Bacteriol. 52:933-938.

Popovici, J., Comte, G., Bagnarol, E., Alloisio, N., Fournier, P., Bellvert, F., Bertrand, C., and Fernandez, M. P. 2010. Differential effects of rare specific flavonoids on compatible and incompatible strains in the Myrica gale-Frankia actinorhizal symbiosis. Appl. Environ. Microbiol. 76:2451-2460.

Prin, Y., Maggia, L., Picard, B., Diem, H. G., and Goullet, P. 1991. Electrophoretic comparison of enzymes from 22 single-spore cultures ob- 
tained from Frankia strain ORS 140102. FEMS (Fed. Eur. Microbiol. Soc.) Microbiol. Lett. 77:223-227.

Safo-Sampah, S., and Torrey, J. 1988. Polysaccharide-hydrolyzing enzymes of Frankia (Actinomycetales). Plant Soil 112:89-97.

Sellstedt, A., Normand, P., and Dawson, J. 2007. Frankia-the friendly bacteria—infecting actinorhizal plants. Physiol. Plant. 130:315-317.

Sen, A., Sur, S., Bothra, A., Benson, D., Normand, P., and Tisa, L. 2008. The implication of life style on codon usage patterns and predicted highly expressed genes for three Frankia genomes. Antonie Leeuwenhoek 93:335-346.

Severinov, K., Semenova, E., Kazakov, A., Kazakov, T., and Gelfand, M. S. 2007. Low-molecular-weight post-translationally modified microcins. Mol. Microbiol. 65:1380-1394.

Shao, Z., Blodgett, J. A., Circello, B. T., Eliot, A. C., Woodyer, R., Li, G., van der Donk, W. A., Metcalf, W. W., and Zhao, H. 2008. Biosynthesis of 2-hydroxyethylphosphonate, an unexpected intermediate common to multiple phosphonate biosynthetic pathways. J. Biol. Chem. 283:23161-23168.

Soltis, D. E., Soltis, P. S., Morgan, D. R., Swensen, S. M., Mullin, B. C., Dowd, J. M., and Martin, P. G. 1995. Chloroplast gene sequence data suggest a single origin of the predisposition for symbiotic nitrogen fixation in angiosperms. Proc. Natl. Acad. Sci. U.S.A. 92:2647-2651.

Stiens, M., Schneiker, S., Puhler, A., and Schluter, A. 2007. Sequence analysis of the 181-kb accessory plasmid pSmeSM11b, isolated from a dominant Sinorhizobium meliloti strain identified during a long-term field release experiment. FEMS (Fed. Eur. Microbiol. Soc.) Microbiol. Lett. 271:297-309.

Svistoonoff, S., Gherbi, H., Nambiar-Veetil, M., Zhong, C., Michalak, Z., Laplaze, L., Vaissayre, V., Auguy, F., Hocher, V., Doumas, P., Bonneau, J., Bogusz, D., and Franche, C. 2010. Contribution of transgenic Casuarinaceae to our knowledge of the actinorhizal symbioses. Symbiosis 50:3-11.

Swensen, S., and Benson, D. R. 2008. Evolution of actinorhizal host plants and Frankia endosymbionts. Pages 73-104 in: Nitrogen-Fixing Actinorhizal Symbioses. K. Pawlowski and W. E. Newton, eds. Springer, Dordrecht, The Netherlands.

Tice, H., Mayilraj, S., Sims, D., Lapidus, A., Nolan, M., Lucas, S., Del Rio, T. G., Copeland, A., Cheng, J. F., and Meincke, L. 2010. Complete genome sequence of Nakamurella multipartita type strain (Y-104T). Stand. Gen. Sci. 2:168.

Udwary, D. W., Gontang, E. A., Jones, A. C., Jones, C. S., Schultz, A. W. Winter, J. M., Yang, J. Y., Beauchemin, N., Capson, T. L., Clark, B. R., Esquenazi, E., Eustaquio, A. S., Freel, K., Gerwick, L., Gerwick, W. H., Gonzalez, D., Liu, W. T., Malloy, K. L., Maloney, K. N., Nett, M., Nunnery, J. K., Penn, K., Prieto-Davo, A., Simmons, T. L., Weitz, S.,
Wilson, M. C., Tisa, L. S., Dorrestein, P. C., and Moore, B. S. 2011. Comparative genomic and proteomic analysis of the actinorhizal symbiont Frankia reveals significant natural product biosynthetic potential. Appl. Environ. Microbiol. 77:3617-3625.

Urzi, C., Brusetti, L., Salamone, P., Sorlini, C., Stackebrandt, E., and Daffonchio, D. 2001. Biodiversity of Geodermatophilaceae isolated from altered stones and monuments in the Mediterranean basin. Environ. Microbiol. 3:471-479.

Valkovicova, L., Valkova, D., Vavrova, S., Alekhina, O., Hoang, V., Jezna, M., and Turna, J. 2011. The role of TerW protein in the tellurite resistance of uropathogenic Escherichia coli. Biologia 66:565-573-573.

Valverde, C., and Huss-Danell, K. 2008. Carbon and nitrogen metabolism in actinorhizal nodules. Pages 167-198 in: Nitrogen-Fixing Actinorhizal Symbioses. K. Pawlowski and W. E. Newton, eds. Springer, Dordrecht, The Netherlands.

Wall, L. G., and Berry, A. M. 2008. Early interactions, infection and nodulation in actinorhizal symbiosis. Pages 147-166 in: Nitrogen-Fixing Actinorhizal Symbioses. K. Pawlowski and W. E. Newton, eds. Springer, Dordrecht, The Netherlands.

Wang, Z., Gerstein, M., and Snyder, M. 2009. RNA-Seq: A revolutionary tool for transcriptomics. Nat Rev Genet 10:57-63.

Weber, T., Rausch, C., Lopez, P., Hoof, I., Gaykova, V., Huson, D. H., and Wohlleben, W. 2009. CLUSEAN: A computer-based framework for the automated analysis of bacterial secondary metabolite biosynthetic gene clusters. J. Biotechnol. 140:13-17.

Wheeler, C. T., Crozier, A., and Sandberg, G. 1984. The biosynthesis of indole-3-acetic acid by Frankia. Plant Soil 78:99-104.

Wheeler, C. T., Akkermans, A. D. L., and Berry, A. M. 2008. Frankia and actinorhizal plants: A historical perspective. Pages 1-24 in: NitrogenFixing Actinorhizal Symbioses. K. Pawlowski and W. E. Newton, eds. Springer, Dordrecht, The Netherlands.

Wu, X., Flatt, P. M., Xu, H., and Mahmud, T. 2009. Biosynthetic gene cluster of cetoniacytone $\mathrm{A}$, an unusual aminocyclitol from the endosymbiotic Bacterium Actinomyces sp. Lu 9419. Chembiochem 10:304-314.

Yamaura, M., Uchiumi, T., Higashi, S., Abe, M., and Kucho, K. 2010. Identification by suppression subtractive hybridization of Frankia genes induced under nitrogen-fixing conditions. Appl. Environ. Microbiol. 76:1692-1694.

Zhang, X., and Benson, D. R. 1992. Utilization of amino acids by Frankia sp. strain CpI1. Arch. Microbiol. 158:256-261.

Zhi, X. Y., Li, W. J., and Stackebrandt, E. 2009. An update of the structure and 16S rRNA gene sequence-based definition of higher ranks of the class Actinobacteria, with the proposal of two new suborders and four new families and emended descriptions of the existing higher taxa. Int. J. Syst. Evol. Microbiol. 59:589-608. 